\title{
Extracorporeal Membrane Oxygenation for Congenital Diaphragmatic Hernia: A Single Center Experience in Turkey
}

\begin{tabular}{|c|}
\hline Ulas Kumbasar ${ }^{1}$, [MD] \\
\hline ORCID: 0000-0003-0616-1326 \\
\hline Ahmet Aydin ${ }^{2},[\mathrm{MD}]$ \\
\hline ORCID: 0000-0002-4046-1982 \\
\hline Zeynelabidin Ozturk ${ }^{3},[\mathrm{MD}]$ \\
\hline ORCID: 0000-0001-8548-4144 \\
\hline Recep Oktay Peker²,[MD] \\
\hline ORCID: 0000-0001-5392-212X \\
\hline Saniye Ekinci ${ }^{4},[\mathrm{MD}]$ \\
\hline ORCID: 0000-0002-2961-7069 \\
\hline Benan Bayrakci ${ }^{3},[\mathrm{MD}]$ \\
\hline ORCID: 0000-0003-3307-0948 \\
\hline Mustafa Yilmaz², [MD] \\
\hline ORCID: 0000-0003-4541-172X \\
\hline Riza Dogan¹, [MD] \\
\hline ORCID: 0000-0003-4845-3044 \\
\hline${ }^{1}$ Department of Thoracic Surgery, Hacettepe University \\
\hline Faculty of Medicine, Ankara, Turkey \\
\hline${ }^{2}$ Department of Cardiovascular Surgery, Hacettepe \\
\hline University Faculty of Medicine, Ankara, Turkey \\
\hline${ }^{3}$ Division of Pediatric Intensive Care, Department of \\
\hline Pediatrics, Hacettepe University Faculty of Medicine, \\
\hline Ankara, Turkey \\
\hline${ }^{4}$ Department of Pediatric Surgery, Hacettepe University \\
\hline
\end{tabular}

${ }^{*}$ Corresponding author: Zeynelabidin Ozturk,

Division of Pediatric Intensive Care, Department of Pediatrics, Hacettepe University Faculty of Medicine, Sihhiye, 06100, Ankara, Turkey.

e-mail address: zeynelabidin_ozturk@hotmail.com

Telephone number: +90 5066174402

\section{wa A B TRACT Ceen}

Objective: Extracorporeal membrane oxygenation is a temporary life-support modality offered for stabilizing neonates with congenital diaphragmatic hernia who are in a critical condition and unresponsive to optimal medical therapy. The aim of this study was to examine our institutional outcomes of early congenital diaphragmatic hernia repair on extracorporeal membrane oxygenation.

Materials and Methods: A total of 17 extracorporeal membrane oxygenation-supported patients with congenital diaphragmatic hernia were evaluated and the demographic, diagnostic, laboratory, clinical data, complications and outcome of the patients were reported.

Results: The study consisted of 7 females and 10 males. Mean birth weight was 3107 g (range, 2360-3840 g). Median age of extracorporeal membrane oxygenation initiation was 2.1 days. In total four patients received venovenous extracorporeal membrane oxygenation. Other patients received venoarterial extracorporeal membrane oxygenation via aortic and right atrial cannulation. The mean duration of extracorporeal membrane oxygenation was 25 days (range: 1-140 days). Six patients (35.2\%) could be weaned from extracorporeal membrane oxygenation. The most common extracorporeal membrane oxygenation related complications were hemorrhage, disseminated intravascular coagulation and limb ischemia $(64.7 \%, 41.1 \%$ and $29.4 \%$, respectively). Diaphragmatic defect was repaired via a subcostal incision in 12 of 13 patients. In $88.2 \%$ of patients diaphragmatic repair was performed with polytetrafluoroethylene patch. In $77 \%$ of patients early congenital diaphragmatic hernia repair was performed concomitantly with extracorporeal membrane oxygenation insertion. The survival rate was $17.6 \%$

Conclusion: Early repair of congenital diaphragmatic hernia in neonates on extracorporeal membrane oxygenation can be associated with high rates of morbidity and mortality. However, extracorporeal membrane oxygenation may be considered a life-saving measure for patients with congenital diaphragmatic hernia who would have otherwise not been salvageable.

Keywords: Congenital diaphragmatic hernia, extracorporeal membrane oxygenation, newborn, surgery

Received: 27 March 2020, Accepted: 23 April 2020,

Published online: 21 May 2020

\section{INTRODUCTION}

Congenital diaphragmatic hernia $(\mathrm{CDH})$ is a severe and complex congenital anomaly occurs approximately 1 in every 2500 to 3000 live births [1]. Despite the advances in medical and surgical techniques and neonatal care capabilities overall survival rate for $\mathrm{CDH}$ is still high. Both pulmonary hypoplasia and persistent pulmonary hypertension are considered to be the principal factors determining the survival. 
Consequently, a considerable amount of neonates with $\mathrm{CDH}$ and persistent pulmonary hypertension may necessitate additional support to provide sufficient tissue oxygenation and perfusion [2, 3]. In such patients who have unstable hemodynamic parameters and low saturations despite optimal medical management and ventilation support, extracorporeal membrane oxygenation (ECMO), which is a temporary and modified form of cardiopulmonary bypass, should be considered as a bridging strategy until patient stabilization $[4,5]$.

Although management with ECMO has been proven to be associated with better overall survival in patients with $\mathrm{CDH}$, it carries a mortality rate reaching up to $50 \%$ primarily due to the systemic anticoagulation-related risk of bleeding [6-8].

Most reports regarding the use of ECMO in $\mathrm{CDH}$ neonates are from the USA. There are fewer papers reported in Asia and Europe [9-11]. In recent years, the use of ECMO reported in Turkey has been involving adult patients primarily. Despite pediatric ECMO applications have been increasing in Turkey, there is only one study mentioning the use of ECMO in $\mathrm{CDH}$ to our knowledge [12]. The purpose of our study is to report our experience with the use of ECMO in $\mathrm{CDH}$ patients and its outcomes. We are not aware of any previous report emphasizing the results of ECMO usage in patients with CDH in Turkey.

\section{MATERIALS and METHODS}

Data of 17 neonates who were operated for CDH were analyzed. In addition to patient characteristics, data were collected including the following variables: Associated cardiac comorbidity, results of preoperative arterial blood gas analysis, right ventricular systolic pressure values, ventilator management, ECMO timing, cannulation site, duration, and complications, surgical technique preference for hernia repair, application of post ECMO stem-cell therapy and in-hospital mortality. Survival status was determined from the date of the last follow-up. The neonates were admitted to the neonatal intensive care unit after delivery. Patients with hemodynamic compromise and respiratory distress were stabilized using usual medical therapy and ventilation support. Indication for ECMO in $\mathrm{CDH}$ patients was failure of conventional medical management strategies. Patients with life-threatening congenital anomalies, uncontrolled bleeding, and irreversible brain damage were excluded.

ECMO cannulations were performed by pediatric cardiovascular surgeons in the operation room. Hernia repair was performed by pediatric surgeons either concomitantly with or several days after the ECMO cannulation. In our institution, the preferred ECMO strategy and cannulation method for neonates with $\mathrm{CDH}$ were venoarterial (VA) ECMO and central cannulation through the ascending aorta and right atrium, respectively. The ECMO circuit included a centrifugal pump and a hollow-fiber membrane oxygenator with an integrated heat exchanger.

Statistical analysis was performed using SPSS 21 for Windows (SPSS Inc., Chicago, IL, USA). The demographic and clinical findings of the patients were described with rates and percentages, mean, and median values.

\section{RESULTS}

The study consisted of 7 females and 10 males. Mean birth weight (BW) was $3107 \mathrm{~g}$ (range, 2360$3840 \mathrm{~g}$ ). CDH was left sided in $88 \%$ of patients. Mean right ventricular systolic pressure was calculated as $63.8 \mathrm{mmHg}$ (range, $35-85 \mathrm{mmHg}$ ). The basic demographic data are summarized in Table 1. Measurements of $\mathrm{pH}, \mathrm{PCO} 2, \mathrm{PO} 2$ and oxygen saturation values in arterial blood analysis before initiation of ECMO were $7.13 \pm 0.19,67.47 \pm 26.9,47.9 \pm$ 23.2 and $76.46 \pm 11.9$, respectively. 
Table 1. Patient characteristics and demographic data.

\begin{tabular}{|c|c|c|c|c|c|}
\hline Patient no & Sex & BBW (g) & CDH side & $\begin{array}{c}\text { Additional cardiac } \\
\text { anomalies }\end{array}$ & $\begin{array}{c}\text { RV systolic pressure } \\
(\mathrm{mmHg})\end{array}$ \\
\hline$\# 1$ & $\mathrm{~F}$ & 3260 & Left & ASD, PDA, TR & 70 \\
\hline$\# 2$ & M & 3200 & Left & ASD, PDA, TR, MR & 70 \\
\hline \#3 & $\mathrm{F}$ & 3840 & Left & TR & 68 \\
\hline$\# 4$ & $\mathrm{~F}$ & 3500 & Left & ASD, PDA & 60 \\
\hline$\# 5$ & $\mathrm{~F}$ & 3540 & Right & ASD, PDA & 75 \\
\hline \#6 & $M$ & 2360 & Left & PDA & 80 \\
\hline \#7 & $\mathrm{F}$ & 2580 & Left & MR & 50 \\
\hline$\# 8$ & M & 3180 & Left & $\mathrm{TR}, \mathrm{MR}$ & 70 \\
\hline \#9 & $F$ & 3160 & Left & PDA & 55 \\
\hline \#10 & M & 3200 & Left & PDA & - \\
\hline$\# 11$ & $\mathrm{~F}$ & 2580 & Left & PDA & 50 \\
\hline \#12 & M & 3250 & Left & PDA & - \\
\hline \#13 & M & 2720 & Right & ASD, PDA & 85 \\
\hline \#14 & M & 3000 & Left & MR & 35 \\
\hline \#15 & M & 3470 & Left & PDA, TR & 70 \\
\hline \#16 & M & 3220 & Left & PDA, TR & 55 \\
\hline \#17 & $M$ & 2760 & Left & PDA, MR & 65 \\
\hline
\end{tabular}

F: Female; M: Male; BBW: Birth body weight; $\mathrm{CDH}$ : Congenital diaphragmatic hernia; ASD: Atrial septal defect; PDA: Patent ductus arteriosus; TR: Tricuspid regurgitation; MR: Mitral regurgitation RV: Right ventricle

Table 2 summarizes the details of ECMO run. Median day of ECMO initiation was 2.1 (1-8). Two patients received direct venovenous (VV) (Patients 6 and 16) and the others received VA ECMO via aortic and right atrial cannulation. In two patients (Patients 15 and 17) VA ECMO support was converted to VV due to stable hemodynamic outcome. The mean duration of ECMO was 25 days (range: 1-140 days). Six patients (35.2\%) could be weaned from ECMO. The most common ECMO related complications were hemorrhage, disseminated intravascular coagulation (DIC) and limb ischemia (64.7\%, $41.1 \%$ and $29.4 \%$, respectively). 
Table 2. Details of ECMO run.

\begin{tabular}{|c|c|c|c|c|c|c|}
\hline Patient no & $\begin{array}{l}\text { Timing } \\
\text { (d) }\end{array}$ & Cannulation site & Days on ECMO & Complication & Survived ECMO & Survived to DC \\
\hline \#1 & $2^{\text {nd }}$ & Ao-RA & 74 & DIC, hemorrhage, HIT & + & + \\
\hline \#2 & $3^{\text {rd }}$ & Ao-RA & 15 & Sepsis, hemorrhage, MOF & - & - \\
\hline \#3 & $1^{\text {st }}$ & Ao-RA & 140 & Limb ischemia, HIT, DIC & + & - \\
\hline \#4 & $8^{\text {th }}$ & Ao-RA & 8 & - & + & + \\
\hline \#5 & $1^{\text {st }}$ & Ao-RA & 12 & Hemorrhage, sepsis & - & - \\
\hline \#6 & $1^{\text {st }}$ & Bi-caval dual lumen & 1 & $\begin{array}{l}\text { Hemorrhage, pericardial } \\
\text { tamponade }\end{array}$ & - & - \\
\hline$\# 7$ & $1^{\text {st }}$ & Ao-RA & 8 & DIC, MOF, low output & - & - \\
\hline \#8 & $1^{\text {st }}$ & Ao-RA & 42 & $\begin{array}{l}\text { Limb ischemia, MOF, } \\
\text { hemorrhage }\end{array}$ & - & - \\
\hline \#9 & $4^{\text {th }}$ & Ao-RA & 4 & DIC, hemorrhage & - & - \\
\hline \#10 & $2^{\text {nd }}$ & Ao-RA & 13 & $\begin{array}{c}\text { Limb ischemia, hemorrhage, } \\
\text { low output }\end{array}$ & - & - \\
\hline \#11 & $1^{\text {st }}$ & Ao-RA & 1 & Limb ischemia, hemorrhage & - & - \\
\hline$\# 12$ & $1^{\text {st }}$ & Ao-RA & 29 & $\begin{array}{c}\text { Limb ischemia, hemorrhage, } \\
\text { MOF }\end{array}$ & - & - \\
\hline \#13 & $1^{\text {st }}$ & Ao-RA & 2 & Hemorrhage, low output & - & - \\
\hline$\# 14$ & $1^{\text {st }}$ & Ao-RA & 3 & SIRS & - & - \\
\hline$\# 15^{*}$ & $3^{\text {rd }}$ & $\begin{array}{c}\text { Ao-RA/ Bi-caval dual } \\
\text { lumen }\end{array}$ & $26 / 4$ & Capillary leak, DIC & + & + \\
\hline \#16 & $4^{\text {th }}$ & Bi-caval dual lumen & 25 & Hemorrhage, DIC & + & - \\
\hline$\# 17^{*}$ & $2^{\text {nd }}$ & $\begin{array}{c}\text { Ao-RA/ Bi-caval dual } \\
\text { lumen }\end{array}$ & $22 / 16$ & DIC, sepsis & + & - \\
\hline
\end{tabular}

V: Venous; Ao: Aorta; RA: Right atrium; ECMO: Extracorporeal Membrane Oxygenation; HIT: Heparin induced thrombocytopenia; DIC: Disseminated intravascular coagulation, MOF: Multi-organ failure, SIRS: Systemic inflammatory response syndrome * ECMO strategy was converted from Ao-RA VA to bicaval venovenous.

Diaphragmatic defect was repaired via a subcostal incision in 12 out of 13 patients. In $88.2 \%$ of patients diaphragmatic repair was performed with polytetrafluoroethylene surgical patch (Gore-Tex ${ }^{\circledast}$ patch; W. L. Gore and Associates). Two patients received primary closure of the diaphragm. In $77 \%$ of patients early $\mathrm{CDH}$ repair was performed concomitantly with ECMO insertion. The repair was delayed until the 5th day of ECMO run in three patients (Patients 8, 10 and 17). We were unable to perform the repair in four patients due to severe cardiac tamponade which leads to sudden cardiac death (Patient 6), severe disseminated intravascular coagulation (Patients 9 and 13) and severe sepsis (Patient 14). Seventy-six percent of patients received continuous venovenous hemodiafiltration (CVVHDF) and/ or plasma exchange (PE) during ECMO run. The survival rate was $17.6 \%$ (Patients 1, 4 and 15). Details of surgical repair, additional therapies, and outcome of patients are summarized in Table 3. 
Table 3. Surgical repair, additional therapies, and outcome.

\begin{tabular}{|c|c|c|c|c|c|}
\hline $\begin{array}{l}\text { Patient } \\
\text { no. }\end{array}$ & Repair incision & Repair time (d) & $\begin{array}{c}\text { Additional ventilation } \\
\text { support }\end{array}$ & CVVHDF and/or PE & Stem-cell Therapy \\
\hline$\# 1$ & $\begin{array}{l}\text { Median } \\
\text { sternotomy }\end{array}$ & Early & HFOV & CVVHDF & + \\
\hline \#2 & Subcostal & Early & - & CVVHDF & - \\
\hline \#3 & Subcostal & Early & HFOV & CVVHDF, PE & + \\
\hline$\# 4$ & Subcostal & Early & HFOV & - & - \\
\hline \#5 & Subcostal & Early & - & CVVHDF, PE & - \\
\hline \#6 & - & - & - & - & - \\
\hline \#7 & Subcostal & Early & HFOV & CVVHDF & - \\
\hline$\# 8$ & Subcostal & Late & HFOV & CVVHDF, PE & + \\
\hline \#9 & - & - & - & PE & - \\
\hline \#10 & Subcostal & Late & - & CVVHDF, PE & + \\
\hline$\# 11$ & Subcostal & Early & HFOV & - & - \\
\hline \#12 & Subcostal & Early & HFOV & & + \\
\hline \#13 & - & - & HFOV & CVVHDF & - \\
\hline$\# 14$ & - & - & HFOV & CVVHDF & - \\
\hline \#15 & Subcostal & Early & HFOV & CVVHDF & - \\
\hline \#16 & Subcostal & Early & - & - & - \\
\hline \#17 & Subcostal & Late & HFOV & CVVHDF & + \\
\hline
\end{tabular}

HFOV: high frequency oscillatory ventilation, CVVHDF: continuous venovenous hemodiafiltration, PE: plasma exchange

\section{DISQUSSION}

$\mathrm{CDH}$ is a developmental failure of the diaphragm due to incomplete fusion of elements structuring the diaphragm. It occurs most frequently in the left side and associated with the herniation of the abdominal viscera into the chest cavity. Decreased surface area of the alveoli and the vascular bed (lung hypoplasia), the development of the abnormal pulmonary vasculature, which is more prone to developing resistance and activation of thromboxane synthetase pathways lead to persistent pulmonary hypertension and respiratory failure, subsequently $[5,13,14]$. Management of the respiratory failure in $\mathrm{CDH}$ is complicated and includes both ventilation and pharmacological methods. The initiation of high-frequency oscillatory ventilation (HFOV), is pivotal. Inhaled nitric oxide (iNO) and administration of surfactant may improve oxygenation. Parallel to the advancements of these strategies worldwide uses of 
ECMO for neonatal acute hypoxic respiratory failure reduced in the last decades [15-17]. Nevertheless, ECMO is considered the only intervention for infants who continue to demonstrate respiratory or cardiac failure despite optimal medical and/or ventilation support [18].

The first successful use of ECMO in a newborn with cardiopulmonary failure was reported by Bartlett et al. in 1975 [19]. Nowadays, the frequency of ECMO usage for $\mathrm{CDH}$ ranges between $0 \%$ to $61 \%$, with mortality rates of $30 \%$ to $40 \%[2,18,20]$. Although $E C M O$ can be a life-saving intervention and improves survival in newborns with $\mathrm{CDH}$, it embraces substantial complications including major bleeding, intracranial infarct or bleed, seizures, and infection. The rate of these complications increase primarily with prolonged ECMO usage and relevant mortality may reach up to $50 \%[5,21]$. Thus, it is critical to give the decision of ECMO initiation with a multidisciplinary approach. In our study, the decision for all ECMO initiations was made by a multidisciplinary approach with the primary initiative of the intensive care physicians. The optimal timing of repair of diaphragmatic hernia of patients on ECMO is difficult. In 10 patients, diaphragmatic hernia was repaired during the operation for ECMO cannulation. Three patients had surgical repair of hernia on 5th day of ECMO run. Diaphragmatic hernia repair while on ECMO was preferred to restore normal anatomy and prevent complications such as intestinal ischemia and volvulus. Furthermore, to decrease the mechanical compression on lungs and pulmonary circulation may improve respiratory functions earlier. On the other hand, surgical repair of hernia while on ECMO may lead complications associated with bleeding which can be lessened by anticoagulation treatment and tranexamic acid. None of our patients had bleeding during hernia repair.

There are very few randomized studies regarding the use of ECMO in $\mathrm{CDH}$ in the literature and the results are debatable. Survival benefit of ECMO in $\mathrm{CDH}$ could not be demonstrated in a study from the UK. In addition, a meta-analysis of randomized trials was unable to state a survival advantage of ECMO usage in $\mathrm{CDH}$ when compared with neonates managed without ECMO support. Besides, according to the Cochrane review of the randomized studies the advantage of ECMO usage in CDH in debatable [22-24]. Nevertheless, Garcia et al. emphasize ECMO usage in carefully selected patients with $\mathrm{CDH}$ for reversible respiratory disease as a strategy to minimize further barotrauma [25]. Mortality rate was considerably high in our study (82.4\%). DIC, hemorrhage and sepsis, which all are associated with ECMO usage, were the potential causes of mortality. Besides, the average duration of ECMO run ( 25 days) is high in the present study which undoubtedly plays a role in adverse outcomes and complications. In the light of these results, we think that ECMO usage in patients with $\mathrm{CDH}$ is debatable. Estimation of overall outcome is very difficult due to variations of individual responses. Thus, the decision of ECMO initiation should be individualized and considered primarily based on the reversibility of the respiratory problem. We also believe that survival rate could be increased with growing experience, advancements in ECMO technology and application of novel tissue engineering strategies such as stem cell therapy.

\section{UMITATIONS OF THE STUDY}

This is a retrospective study based on a single-institute experience. The study population is very small and there is no control group. Thus, our findings may only reflect the preliminary results of a learning period.

\section{CONAUSION}

ECMO has high morbidity and mortality rates in neonates with $\mathrm{CDH}$ and its survival benefit is unclear. Therefore, further prospective studies with larger patient samples are warranted to evaluate its applicability in patients with $\mathrm{CDH}$. In the meantime, ECMO may be considered a life-saving measure for patients with $\mathrm{CDH}$ who would have otherwise not been salvageable.

\section{CONFUCT OF INTEREST}

The authors declare that they have no conflict of interest. 
[1] Langham MR Jr, Kays DW, Ledbetter DJ, et al. Congenital diaphragmatic hernia. Epidemiology and outcome. Clin Perinatol 1996; 23: 671-88.

[2] Sinha CK, Islam S, Patel S, et al. Congenital diaphragmatic hernia: prognostic indices in the fetal endoluminal tracheal occlusion era. J Pediatr Surg 2009; 44: 312-6.

[3] Partridge EA, Peranteau WH, Rintoul NE, et al. Timing of repair of congenital diaphragmatic hernia in patients supported by extracorporeal membrane oxygenation (ECMO). J Pediatr Surg 2015; 50: 260-2.

[4] Khan AM, Lally KP. The role of extracorporeal membrane oxygenation in the management of infants with congenital diaphragmatic hernia. Semin Perinatol 2005; 29: 118-22.

[5] McHoney M, Hammond P. Role of ECMO in congenital diaphragmatic hernia. Arch Dis Child Fetal Neonatal Ed 2018; 103: F178-F181.

[6] Guner YS, Khemani RG, Qureshi FG, et al. Outcome analysis of neonates with congenital diaphragmatic hernia treated with venovenous vs venoarterial extracorporeal membrane oxygenation. J Pediatr Surg 2009; 44: 1691-701.

[7] Hoffman SB, Massaro AN, Gingalewski C, et al. Predictors of survival in congenital diaphragmatic hernia patients requiring extracorporeal membrane oxygenation: CNMC 15-year experience. J Perinatol 2010; 30: 546-52.

[8] Fallon SC, Cass DL, Olutoye OO, et al. Repair of congenital diaphragmatic hernias on Extracorporeal Membrane Oxygenation (ECMO): does early repair improve patient survival? J Pediatr Surg 2013; 48: 1172-6.

[9] Inamura N, Usui N, Okuyama H, et al. Extracorporeal membrane oxygenation for congenital diaphragmatic hernia in Japan. Pediatr Int 2015; 57: 682-6.

[10] Mugford M, Elbourne D, Field D. Extracorporeal membrane oxygenation for severe respiratory failure in newborn infants. Cochrane Database Syst Rev 2008; 3: CD001340.

[11] Hung WT, Huang SC, Mazloum DE, et al. Extracorporeal membrane oxygenation for neonatal congenital diaphragmatic hernia: The initial single-center experience in Taiwan. J Formos Med Assoc 2017; 116: 333-9.

[12] Okulu E, Atasay FB, Tunç G, et al. Extracorporeal membrane oxygenation support in neonates: a single center experience in Turkey. Turk J Med Sci 2018; 48: 223-30.

[13] Rothenbach P, Lange P, Powell D. The use of extracorporeal membrane oxygenation in infants with congenital diaphragmatic hernia. Semin Perinatol 2005; 29: 40-4.
[14] Stolar CJ, Dillon PW, Stalcup SA. Extracorporeal membrane oxygenation and congenital diaphragmatic hernia: modification of the pulmonary vasoactive profile. J Pediatr Surg 1985; 20: 681-3.

[15] Neonatal Inhaled Nitric Oxide Study Group. Inhaled nitric oxide in full-term and nearly full-term infants with hypoxic respiratory failure. N Engl J Med 1997; 336: 597-604.

[16] Hintz SR, Suttner DM, Sheehan AM, et al. Decreased use of neonatal extracorporeal membrane oxygenation (ECMO): how new treatment modalities have affected ECMO utilization. Pediatrics 2000; 106: 1339-43.

[17] Paden ML, Conrad SA, Rycus PT, et al; ELSO Registry. Extracorporeal Life Support Organization Registry Report 2012. ASAIO J 2013; 59: 202-10.

[18] Logan JW, Rice HE, Goldberg RN, et al. Congenital diaphragmatic hernia: a systematic review and summary of best-evidence practice strategies. J Perinatol 2007; 27: 535-49.

[19] Bartlett RH. Esperanza. Presidential address. Trans Am Soc Artif Intern Organs 1985; 31: 723-6.

[20] Seetharamaiah R, Younger JG, Bartlett RH, et al; Congenital Diaphragmatic Hernia Study Group. Factors associated with survival in infants with congenital diaphragmatic hernia requiring extracorporeal membrane oxygenation: a report from the Congenital Diaphragmatic Hernia Study Group. J Pediatr Surg 2009; 44: 1315-21.

[21] Vaja R, Bakr A, Sharkey A, et al. The use of extracorporeal membrane oxygenation in neonates with severe congenital diaphragmatic hernia: a 26-year experience from a tertiary centre. Eur J Cardiothorac Surg 2017; 52: 552-7.

[22] Davis PJ, Firmin RK, Manktelow B, et al. Long-term outcome following extracorporeal membrane oxygenation for congenital diaphragmatic hernia: the UK experience. J Pediatr 2004; 144: 309-15.

[23] Elbourne D, Field D, Mugford M. Extracorporeal membrane oxygenation for severe respiratory failure in newborn infants. Cochrane Database Syst Rev 2002; 1: CD001340.

[24] Morini F, Goldman A, Pierro A. Extracorporeal membrane oxygenation in infants with congenital diaphragmatic hernia: a systematic review of the evidence. Eur J Pediatr Surg 2006; 16: 385-91.

[25] Garcia A, Stolar CJ. Congenital diaphragmatic hernia and protective ventilation strategies in pediatric surgery. Surg Clin North Am 2012; 92: 659-68, ix. 